\title{
VII CINCCI
}

VII Colóquio internacional sobre Comércio e Cidade

Fortaleza, 03 a 07 de Novembro de 2020

\section{Avaliação da integridade da paisagem urbana histórica da Avenida Higienópolis (Londrina, PR): alcances e limites metodológicos}

Evaluation of the integrity of the historic urban landscape of Higienópolis Avenue (Londrina, PR): scope and methodological limits

Evaluación de la integridad del paisaje urbano histórico de la Avenida Higienópolis (Londrina, PR): alcance y límites metodológicos

BRANDÃO, Marília L.; Graduada; Universidade Estadual de Londrina (UEL) marilialombardibrandao@gmail.com

RODRIGUES, Eloisa R. R.; Doutora; Universidade Estadual de Londrina (UEL) eloribeiro@uel.br

SANTOS, Ana Claudia de S.; Mestranda; Universidade Estadual de Londrina (UEL) ana.claudia@uel.br

\section{Resumo}

Ao avaliar a evolução da paisagem urbana histórica em um trecho da Avenida Higienópolis (Londrina, PR), este trabalho busca identificar as mutações, permanências totais e parciais de seu tipo-base formador, questionando motivo e período em que ocorreram. Para responder a tais questionamentos utiliza-se a abordagem da Morfologia Urbana, observando 106 lotes dispostos em 14 quadras. Verificou-se um acentuado processo de adaptação de edificações residenciais pioneiras para atender fins comerciais, em três diferentes graus de adaptação. Discute-se que, o processo acelerado de adaptação de edificações históricas, em conjunto com a ausência de políticas e instrumentos mais eficazes de preservação tem resultado em perdas significativas da integridade da paisagem urbana histórica. Como contribuição final tem-se a verificação da aplicabilidade e adaptação metodológica de métodos oriundos da escola inglesa de morfologia urbana.

Palavras-chave: Morfologia Urbana. Processo tipológico. Residências históricas de Londrina.

Evaluation of the integrity of the historic urban landscape of Higienópolis Avenue (Londrina, PR): scope and methodological limits

\section{Abstract}


VII Colóquio internacional sobre Comércio e Cidade

When evaluating the evolution of the historic urban landscape in a stretch of Higienópolis Avenue (Londrina, PR), this work seeks to identify the mutations, total and partial permanences of its base-forming type, questioning the reason and period in which they occurred. To answer these questions, the Urban Morphology approach is used, observing 106 lots arranged in 14 blocks. There was a marked process of adaptation of pioneer residential buildings to serve commercial purposes, in three different degrees of adaptation. It is argued that the accelerated process of adapting historic buildings, together with the absence of more effective policies and instruments for preservation, has resulted in significant losses in the integrity of the historic urban landscape. As a final contribution we have the verification of the applicability and methodological adaptation of methods from the English school of urban morphology.

Keywords: Urban Morphology. Typological process. Historic residences in Londrina.

\section{Evaluación de la integridad del paisaje urbano histórico de la Avenida Higienópolis (Londrina, PR): alcance y límites metodológicos}

\section{Resumen}

Al evaluar la evolución del paisaje urbano histórico en un tramo de la Avenida Higienópolis (Londrina, PR), este trabajo busca identificar las mutaciones, las permanencias totales y parciales de su tipo de formación de base, cuestionando la razón y el período en que ocurrieron. Para responder a estas preguntas, se utiliza el enfoque de morfología urbana, observando 106 lotes dispuestos en 14 bloques. Hubo un marcado proceso de adaptación de edificios residenciales pioneros para fines comerciales, en tres grados diferentes de adaptación. Se argumenta que el proceso acelerado de adaptación de edificios históricos, junto con la ausencia de políticas e instrumentos más efectivos para la preservación, ha resultado en pérdidas significativas en la integridad del paisaje urbano histórico. Como contribución final tenemos la verificación de la aplicabilidad y la adaptación metodológica de los métodos de la escuela de morfología urbana en inglés.

Palabras clave: Morfología Urbana. Proceso tipológico. Residencias históricas en Londrina. 


\section{Introdução}

Apesar de relativamente nova, Londrina é uma cidade que se destacou das demais cidades da ocupação norte paranaense devido à explosão demográfica e crescente concentração de capital. A terra roxa, típica da região fértil e próspera, impulsionou o desenvolvimento do setor agrícola, estimulou a produção de café (por anos a principal cultura), e colaborou para afirmar a cidade enquanto núcleo urbano que se diversificou com o passar do tempo (CASTELNOU, 2002). Após altos e baixos da agricultura, Londrina começa a se transformar no que se conhece atualmente, uma cidade cujo protagonismo da atividade comercial vem sendo um dos principais fatores de desenvolvimento econômico, mas ao mesmo tempo, uma ameaça à integridade da paisagem urbana histórica.

Nesta mesma década (1970) a densidade populacional da cidade aumenta, sendo acompanhada pela expansão e diversificação do setor terciário. Ambos processos impulsionaram a transformação da paisagem urbana histórica da Avenida Higienópolis, modificando sensivelmente sua conformação, e comprometendo seu caráter histórico. A verticalização da área central, intensificada a partir de 1980, soma-se a este processo, em que muitas edificações residenciais originais sucumbiram ao crescimento urbano, e desapareceram, e outras vem sendo mal adaptadas.

A necessidade de adaptação de edificações residenciais unifamiliares para fins comerciais expõe a vulnerabilidade do patrimônio edificado frente ao avanço da cultura de consumo contemporânea, e exigências impostas pelo segmento varejista (RODRIGUES, 2012). Exemplo disso é a (questionável) qualidade arquitetônica empregada na adaptação de fachadas, tornando-as genéricas, e até mesmo anacrônicas. Infere-se, portanto, que a adaptação sistemática do tipo-base edilício (a residência unifamiliar) que opera na Avenida Higienópolis constitui um aspecto chave observado neste processo de transformação, comprometendo a integridade da paisagem urbana histórica, e resultando em perdas irreparáveis ao caráter histórico do centro de Londrina.

Isto posto, a pesquisa visa refletir sobre este fenômeno, analisando seus componentes e avaliando alcances e limites da abordagem metodológica sugerida. Com isso, busca-se observar se o método é suficiente para responder, pelo menos em partes, alguns dos questionamentos levantados pela investigação, a saber: quais foram, e como ocorreram as modificações no tecido urbano na área central de Londrina, e em particular na Avenida Higienópolis? Como o tipo-base, construído a partir de 1936, vem sendo adaptado? Qual o papel da atividade comercial neste processo?

Para atingir tais objetivos, utiliza abordagens da Morfologia Urbana, combinando métodos de Yamaki (2008) e Gokce \& Chen (2018) para avaliar o grau da permanência dos elementos constituintes da paisagem urbana histórica na escala do edifício e da rua. Tal abordagem também auxilia a tarefa de classificação das adaptações, em níveis assim determinados: mutação, permanência parcial fraca, permanência parcial forte e permanência total. A avaliação considerou um universo de 106 parcelas (lotes originais), dispostas frontalmente em trecho de 14 quadras da Avenida Higienópolis, contido nos limites do plano histórico de 1932 (Figura 1). As parcelas originais sofreram alterações, e foram reduzidas ao longo dos anos para 75 . Deste total inferiu-se que apenas 
$15,09 \%$ das edificações residenciais unifamiliares puderam ser classificadas como permanências totais ou parciais, e todo restante sofreu mutações.

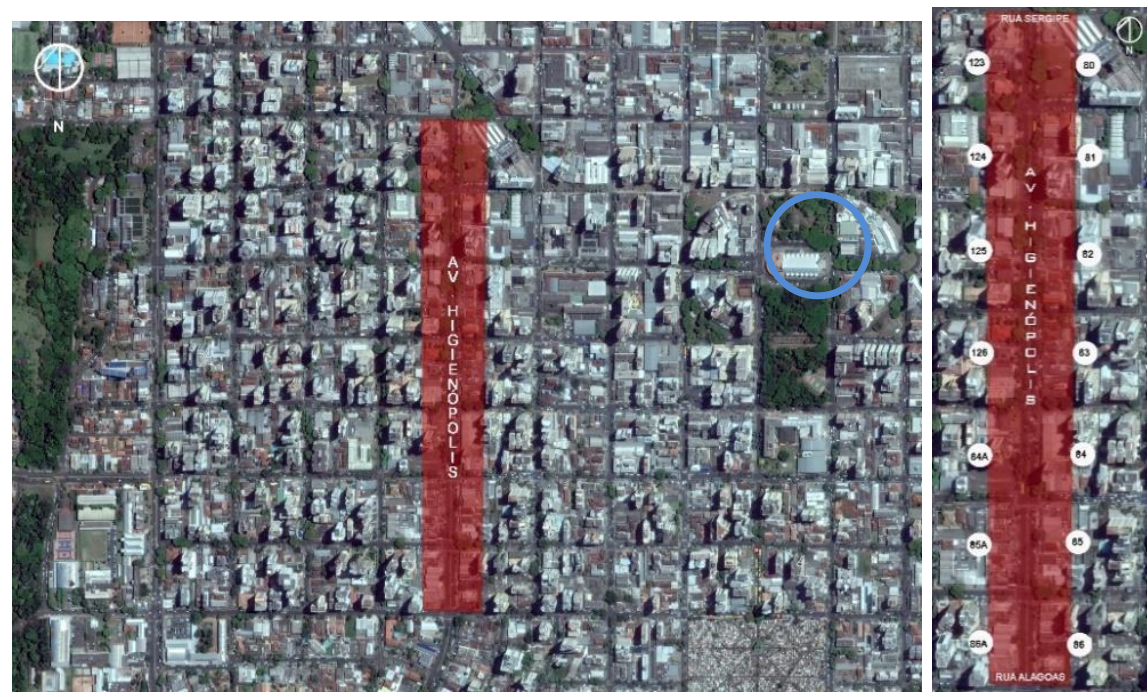

Figura 1: Av. Higienópolis. A esquerda: contexto urbano da avenida em relação à catedral metropolitana (destacada em azul); a direita: quadras do segmento avaliado.

Fonte: Google Earth, adaptado pelas autoras, 2020.

\section{Escopo teórico-metodológico - Morfologia urbana e processo tipológico}

O termo "Morfologia" começa a ser utilizado pelo autor e filósofo Goethe em 1827 para se referir ao estudo do tipo e da unidade, fazendo alusão à forma orgânica, tal como explicam Marsh \& Staedman (1971). Mais tarde, Batty \& Longley (1994) citam que o termo "Morfologia" passa a ser associado ao estudo da relação entre forma e função. Já Larkham \& Jones (1980), referindo-se à forma urbana, indicam que o termo é usado no estudo das relações entre forma edificada, pessoas e processos que os moldam. Em concordância, Costa \& Netto (2015) também se referem ao estudo da forma como meio de investigar as ações sociais edificadas no tempo, evocando o conceito de 'palimpsesto' para se referir à sobreposição de camadas históricas num mesmo local.

A tradicional 'escola inglesa', encabeçada pelo geógrafo M.R.Conzen, sugere o estudo da forma urbana por meio de uma sistematização da paisagem urbana em três partes (visão tripartida). Por esta abordagem a evolução da forma urbana é observada pela relação entre 3 elementos: 1) plano urbano; 2) tecido urbano e 3) uso e ocupação do solo. O primeiro trata do plano bidimensional, sendo o menos suscetível à mudança devido à sua escala. O segundo se refere à relação das edificações com os espaços livres imediatos. E o terceiro e último componente trata o uso da edificação e sua organização espacial, observando-se interferências temporais e aspectos culturais da sociedade no qual foram construídos (NETTO \& COSTA 2015). Este último componente é também o mais 
vulnerável e susceptível na evolução da forma urbana, tendo em vista a dinâmica das atividades econômicas, e em particular do setor terciário.

Conzen (1960) acrescenta ainda a relevância do fator 'historicidade' como agente formador da paisagem urbana. $O$ autor explica que a forma urbana será resultado do contexto cultural e do momento histórico em que se realiza, somados aos acontecimentos anteriores passados no local. Deste modo, a historicidade será compreendida como um dos traços componentes da paisagem urbana, testemunhando os acúmulos e permanências de diferentes momentos históricos, se comportando, como sugere Costa \& Netto (2015) como um palimpsesto.

Avançando nessa teoria, Muratori (1959) incorpora a dimensão física de um 'tipo' para estudar a formação urbana, e declara que as cidades deveriam emergir de tradições históricas e vernaculares. Assim, o modelo a ser construído seria intrínseco a um povo, e se manifestaria em um determinado momento, de forma natural, estando este modelo já enraizado e denominado como "consciência espontânea" (MURATORI, 1959). Um tipo edilício poderia então sofrer variações conforme a necessidade da sociedade na qual se insere (AMORIM \& TANGARI, 2006).

Rossi (1964) contribui neste debate, argumentando que a paisagem urbana é constituída de três escalas (rua, bairro e cidade), em que opera uma ordem social advinda de tensões entre a função econômica e divisão de classes. Neste processo, a especulação imobiliária atuaria como um dos agentes transformadores da cidade, ou seja, estabelecendo, por esta perspectiva, uma relação entre forma urbana e seu contexto sociológico. A partir destes autores denota-se então que a ideia de 'tipo' induz a pensar a forma urbana a partir de forças estabelecidas, além do capital, também por cultura, história, religião, ideologias e práticas construídas durante anos (AMORIM \& TANGARI, 2006).

Como último elemento do escopo teórico, aborda-se o processo tipológico a partir da construção de Gokce \& Chen (2018), em trabalhos desenvolvidos na cidade de Ancara (Turquia). Estas autoras esmiúçam a ideia de 'área cultural', já apresentada por Caniggia \& Maffei (2001) como sendo o recorte tempo-espaço onde tipos edilícios são gerados, transformados ou desintegrados. Para Chen \& Thwaites (2013), por exemplo, ao falar que determinados tipos pertencem a uma mesma área cultural, subentende-se que tais tipos estejam sobre a influência dos mesmos determinantes socioeconômicos. Caniggia \& Maffei (2001) distinguem duas categorias de 'tipo' que podem existir numa área cultural, classificando-os em tipo sincrônico (tipos semelhantes que ocorrem espaços diferentes ao mesmo tempo) e tipo diacrônico, em que as mudanças ocorrem em sequência, fazendo-os atravessar por diferentes períodos. Por este fato, determinados tipos irão perdurar, aparecendo em apenas uma área (por exemplo o casario das cidades italianas tradicionais), enquanto outros serão vistos em diferentes espaços, sendo, no entanto, mais vulneráveis (BURKAY, 2006).

$\mathrm{Na}$ abordagem de Gokce \& Chen (2018) o processo tipológico é estudado em 3 fases: 1) a primeira determina os períodos morfológicos decorridos numa dada área cultural; 2) posteriormente elabora-se um "quadro tipológico", organizando a paisagem urbana em três escalas (edificação, rua e bairro) e temas de análise coerente com as escalas, tais como: permeabilidade, visibilidade, conectividade e sequência espacial para o caso da escala da edificação; 3) por fim, os pares de tipos são comparados entre si, de acordo com a quantidade de transformações ocorridas, mediante o que se classifica o grau de permanências 
das edificações em mutação, continuidade ou continuidade parcial, pelas características determinantes de cada tipo.

Já o método de Yamaki (2008) apresenta estratégias para avaliar a integridade e o caráter histórico da edificação e da paisagem urbana. Segundo este autor, para uma edificação ser considerada histórica ela deve ser pioneira ou uma das primeiras existentes, ter aplicação de saberes tradicionais e ser formadora da identidade local, sendo testemunho de importantes ocorrências do desenvolvimento da cidade. Para esta análise são necessárias 3 etapas: a primeira observa aspectos totais como implantação da edificação, recuos e visibilidade a partir de um determinado distanciamento. Mais próximo da edificação são observados os detalhes da fachada como materiais e ornamentos, realizando assim a segunda etapa, e para a terceira etapa é observado o interior da edificação. Realizado o levantamento, completa-se uma ficha onde cada elemento considerado relevante para o caráter da edificação recebe uma pontuação e a soma da pontuação reflete o nível da integridade da edificação (YAMAKI, 2008).

Pontos de convergência são identificados nestes métodos que ao tentar compreender a formação urbana a partir de uma área cultural, naturalmente, se veem frente a questionamentos como: a qual período morfológico um dado tipo observado pertence? Quais escalas devem ser analisadas e quais serão os parâmetros de investigação de cada uma destas escalas? Como quantificar e avaliar as informações recolhidas nos levantamentos para obter resultados objetivos? Ancorados nos conceitos da Morfologia Urbana ambos autores apontam que a interpretação de camadas históricas através do contexto cultural e social em que estão imersos os tipos edilícios, são uma chave importante na leitura e avaliação da paisagem urbana histórica.

\subsection{Análise da paisagem urbana histórica da Avenida Higienópolis}

Enquadrado no escopo teórico apresentado, a pesquisa e análise da paisagem urbana histórica da Avenida Higienópolis foi iniciada por levantamentos documentais na Biblioteca Municipal e no Museu Histórico de Londrina. Buscando um aprofundamento na história da avenida foram investigadas as plantas e fachadas das residências de cada um dos lotes que compõem as 14 quadras, processo este realizado na Prefeitura Municipal de Londrina no Setor de Documentação e Cadastro Imobiliário. Os levantamentos descritos permitiram a interpretação do tipo-base iniciado no primeiro ciclo de ocupação da avenida, e seu processo evolutivo. Deste modo, investigou-se também os períodos de execução das edificações residenciais, avaliando-se a década com maior predominância construtiva, as edificações residenciais pioneiras, as demolições ocorridas, reconstruções e adaptações.

Relativo ao primeiro elemento constituinte da paisagem urbana, o plano urbano, não foram identificadas modificações. No plano urbano de 1932 identificase apenas as quadras locadas à direita da atual avenida, período em que a denominação da via era "Rua Parahyba". Segundo Zangirolani (2001), a ideia de abertura da Avenida Higienópolis partiu de Eugênio Victor Larionoff, que ao idealizar uma avenida semelhante à Avenida Paulista em São Paulo, fez o pedido aos engenheiros da CTNP Craig Smith e Arthur Thomas que compactuaram com seu desejo. A avenida recebeu então, mais uma vez sobre a influência da capital 
paulista, o nome de Higienópolis, trazendo referência do bairro residencial das classes média e alta (CASTELNOU, 2002). Desta forma, a parte do plano urbano que já estava presente na primeira planta conhecida de Londrina não foi alterada, possuindo $105 \mathrm{~m} \times 135 \mathrm{~m}$, ou seja, dimensões alargadas em comparação ao padrão de quadras do quadrilátero histórico de $105 \mathrm{~m} \times 115 \mathrm{~m}$. As quadras à esquerda da avenida também mantiveram sua medida original de $105 \mathrm{~m} \times 105 \mathrm{~m}$ desde 1936.

Esmiuçando estas investigações sobre o tecido urbano, ou seja, o conjunto e a relação entre quadra, lote e edificação, foi possível notar que houveram transformações desde os primeiros anos. A principal transformação é relativa à junção ou separação dos lotes padrões que consequentemente alteram a escala das edificações e a continuidade da paisagem urbana histórica. No passado, os lotes eram unidos para a construção dos casarões e palacetes, já na atualidade a união de lotes normalmente ocorre para a construção de edifícios verticais ou conjuntos comerciais. Por isso, dos 106 lotes propostos no projeto inicial, atualmente são encontrados apenas 75 , apresentando uma redução de $29,25 \%$ das parcelas.
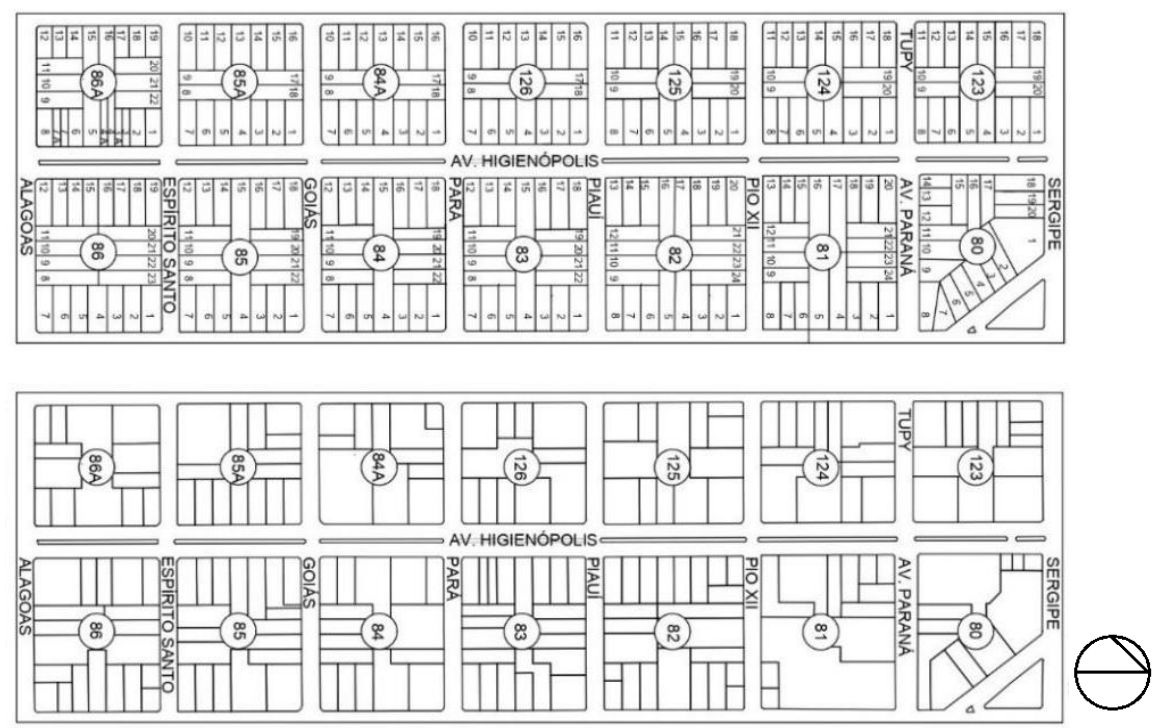

Figura 2: Uniões e segregações de lotes. Acima: Projeto original de 1936. Abaixo: Atualmente.

Fonte: Brandão (2019, p.60).

Outro aspecto diz respeito a alteração das fachadas, cujo padrão inicial, oriundo das residências unifamiliares, foi e ainda é sistematicamente alterado. Observa-se uma modificação drástica neste trecho da avenida, que teve uma mudança em seu perfil de ocupação residencial para predominantemente comercial. Ou seja, a mudança relativa ao uso e à ocupação do solo, relacionada a outros fatores mais amplos da economia urbana, tem ralações estruturais com a modificação da paisagem urbana histórica. Não é garantido afirmar com precisão o momento em que surge a atividade comercial, ou quando dominaram a avenida, pois muitos destes estabelecimentos pertenciam aos mesmos proprietários que abriam pequenos comércios em suas próprias residências.

Com o passar do tempo outros fatores sociais e culturais contribuíram para a transformação dos usos, como por exemplo a crescente movimentação de jovens nos canteiros da avenida a partir da década de 1960. Devido ao fluxo intenso de 
carros que cortavam a cidade pela Avenida Higienópolis traçando rota Norte-Sul, ocorria a utilização dos canteiros centrais da avenida como estacionamento de carros dos jovens que ali se reuniam, fazendo do local o "point" de encontro da cidade. Segundo Boni (2014), essa questão foi muito polêmica no período, envolvendo medidas políticas tais como a elevação do canteiro central e faixas de estacionamento, influenciando também a paisagem urbana histórica.

Já na década de 1980, percebeu-se que a movimentação da avenida se intensificou, repelindo ainda mais muitos dos moradores, que começaram a perder o interesse em ali permanecer. Nesse período a administração da cidade identificava o potencial comercial da avenida, e enquanto os antigos moradores se retiravam, os conjuntos comerciais ocupavam o lugar. Foi na mesma década que se construiu o primeiro edifício vertical da avenida, alinhado com as novas demandas econômicas já dominantes na região central.

É importante colocar que embora muitas vezes citada como avenida nobre onde residiam famílias tradicionais e ricas de Londrina, na realidade os lotes ao redor da avenida foram inicialmente ocupados pelos trabalhadores da CTNP, recebendo os olhares da elite apenas mais tarde, com as construções de casarões como o de Celso Garcia Cid, a bem lembrada "casa dos anões" da família Roherig e o palacete Pedrialli (ZANGIROLANI, 2001). No entanto, Zangirolani (2001) confirma o fato da avenida ter se consolidado como homogeneamente residencial, sobretudo na década de 1940 (Figura 3).

Esta investigação mostrou que o tipo-base formador do tecido urbano da Avenida Higienópolis foi de fato a edificação residencial unifamiliar (pioneira). Identificou também 3 variantes, a saber: residência unifamiliar térrea, residência unifamiliar sobrado e residência unifamiliar mansão. A segunda e a terceira variante se distinguem pela necessidade ou não de união de lotes para sua implantação e, consequentemente, pela dimensão da área da edificação. Atualmente, o tipo-base permaneceu em menor escala (16 parcelas), surgindo outros 2 tipos edilícios: o conjunto comercial e a edificação vertical.

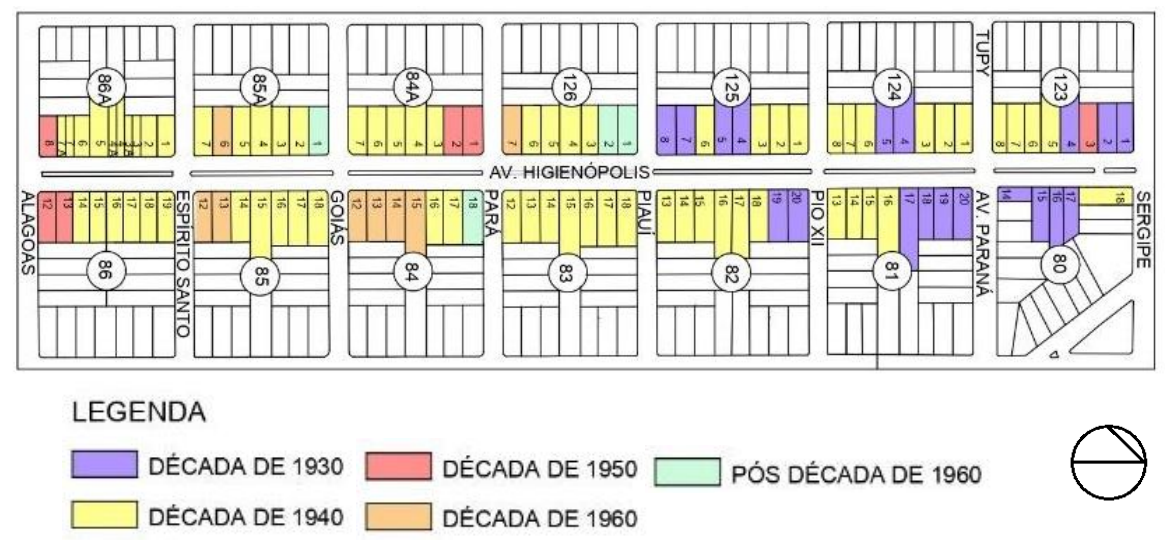

Figura 3: Ocupação da avenida através das décadas.

Fonte: Brandão (2019, p.51).

\subsection{Adaptações - o surgimento de novos tipos e o caráter da edificação histórica}


Dentre os 75 lotes que atualmente constituem as 14 quadras frontais da Avenida Higienópolis, 16 edificações residenciais foram identificadas como "permanência", muito embora seu uso já não seja o mesmo, reforçando a teoria de Conzen (1960), a maioria das edificações residenciais classificadas como permanências - mais especificamente $81,25 \%$ - são utilizadas atualmente para desempenho de atividade comerciais e sofreram desde pouco ou nenhuma adaptação, até adaptação bruscas, e que não permitem mais o reconhecimento da edificação original (Figura 4).

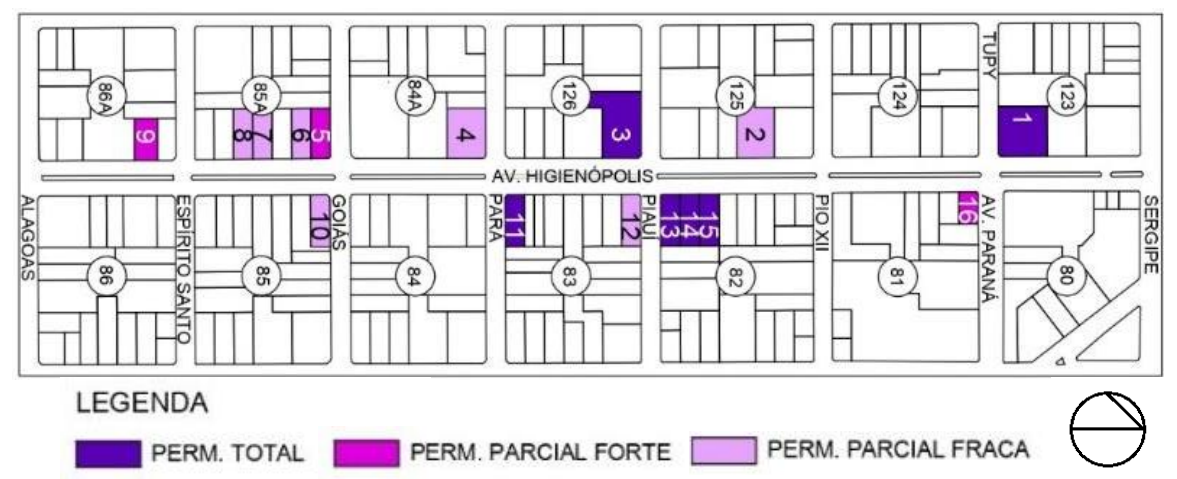

Figura 4: Disposição das permanências restantes na avenida.

Fonte: Brandão, (2019, p.107).

Assim como nos métodos construídos para identificação do processo tipológico dos autores citados anteriormente, tentou-se a distinção de fases ou períodos que ocorreram na área cultural. Considerando que Londrina é uma cidade jovem (85 anos), apenas duas fases destacaram-se em sua conformação, sendo: fase residencial e fase comercial. A pesquisa sugere que o 'ponto de viragem' estipulado, segundo a teoria de Gokce \& Chen (2018), foi o ano de 1978, o momento que marca o fim de um tipo e o início de outro. Essa data marca a conclusão da última edificação residencial executada neste trecho da avenida. $A$ partir deste ponto, as residências passam a ser reformadas ou demolidas para a construção de estabelecimentos comerciais e/ou edificações verticais, e a alteração da paisagem urbana histórica se intensifica.

Além da verificação do ciclo de construção, outros elementos foram apontados como determinantes do caráter histórico da paisagem urbana, como sugere Yamaki (2008). Logo, a avaliação levou em conta aspectos como 1) materiais de acabamento, 2) níveis topográficos, 3) ornamentos, 4) visibilidade, 5) gradis e muros, 6) aberturas, 7) acessos (rampas e escadas), 8) telhados, 9) jardins, 10) recuos e projeções, 11) implantação, 12) volumetria e 13) gabarito. Das 75 ocupações existentes atualmente na avenida, apenas em 16 foram identificadas a permanência de um número suficiente destes elementos, tornandoas reconhecíveis do tipo-base formador (residências unifamiliares). Deve-se destacar que nesta avaliação nenhum elemento foi apontado como mais ou menos relevante, pois são todos importantes na composição arquitetônica da edificação, e na sua inserção urbana.

O processo de avaliação foi realizado a partir da pontuação do grau de permanência destes elementos em cada edificação. Assim, atribui-se pontuação 2 para os casos em que a edificação atual estivesse fiel ao projeto original; 
pontuação 1, para casos com poucas modificações, ou pontuação 0 , para os casos com descaracterização total ou muito significativa. Quando a soma dos elementos contabilizasse entre 26 (pontuação máxima) e 23, apontavam para 0 melhor nível de integridade do edifício histórico (Figura 5.a.). Pontuações menores que 23 pontos e maiores que 18 pontos apontavam para permanências parciais fortes (Figura 5.b.), onde poderiam ser observadas facilmente os elementos originais da edificação. Já as pontuações menores que 18 pontos e maiores que 11 pontos representavam as permanências parciais fracas (Figura 5.c.), ou seja, aquelas que dificilmente poderiam ser entendidas como permanências, necessitando observação por diversos ângulos para identificação dos elementos do projeto original. Com relação a documentação, utilizou-se fichas cadastrais para as duas fases da avenida (anterior e posterior a 1978); imagem da fachada original e atual; implantação e o quadro de avaliação dos elementos arquitetônicos resultando no nível de permanência da edificação.

Após a avaliação das permanências, e de seus devidos graus, é possível observar, que não necessariamente uma quadra com maior número de permanências irá expressar maior nível de integridade da paisagem urbana histórica, pois essa afirmação dependeria da avaliação dos graus descritos anteriormente. Esta verificação está ligada em grande parte com as adaptações comerciais, que em geral promovem modificações na fachada. A quadra 85A, por exemplo, possui 4 permanências parciais, das quais apenas 1 é considerada forte. Em contraponto, a quadra 82 possui menos permanências (3), porém todas são totais e estão dispostas em sequência, o que colabora com a visualização da paisagem urbana histórica.

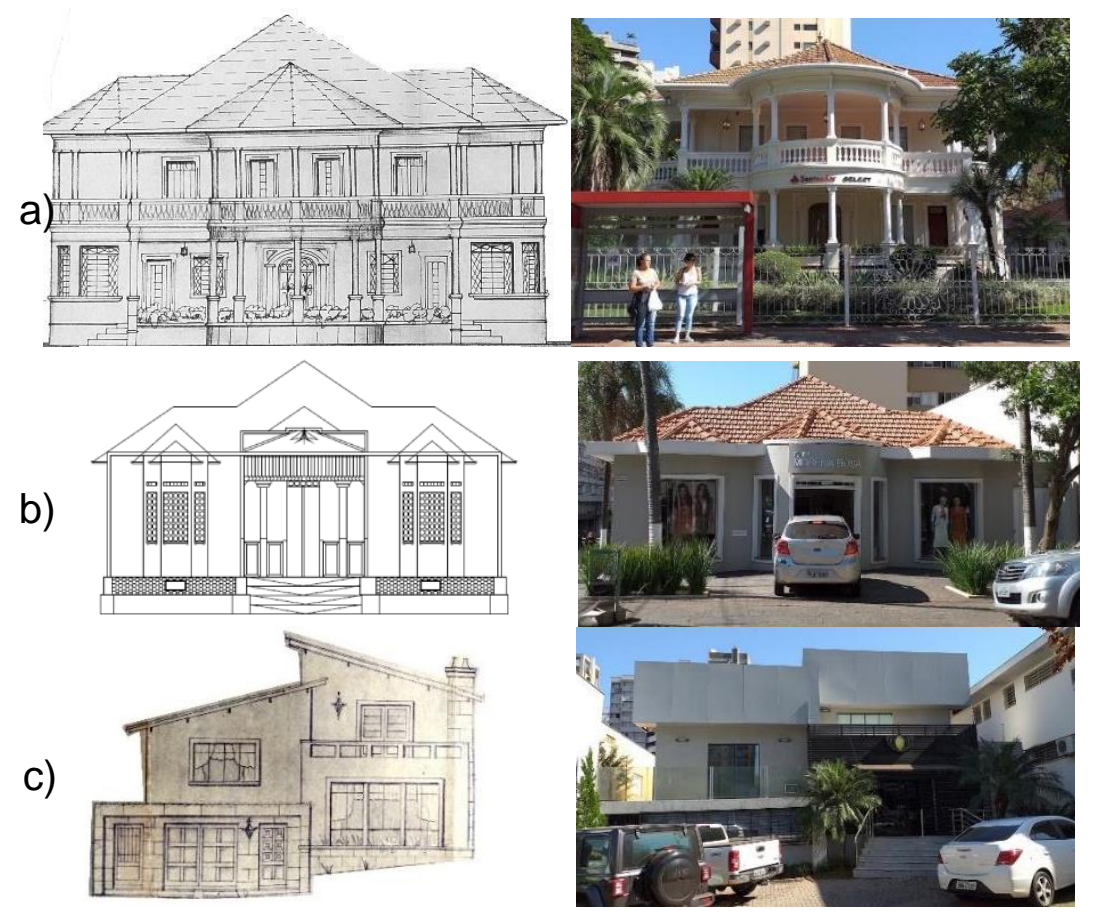

Figura 5: Três níveis de integridade: a) permanência total, b) permanência parcial forte e c) permanência parcial fraca.

Fonte: Fachadas originais a) e c): Cadastro Imobiliário da Prefeitura de Londrina. Fachada original b): Plano Diretor Histórico-Cultural de Londrina. Imagens atuais: Da autora, 2019. 
Observa-se então, que no universo de 75 parcelas atuais, apenas $8 \%$ (6 unidades) representam permanências totais, ou seja, continuidade total dos elementos formadores da paisagem urbana histórica. A continuidade parcial apresenta um percentual de 13,33\% (10 unidades), sendo a soma das permanências parciais fortes e fracas. Deste modo, a taxa de mutação representada por todas as residências que foram demolidas para dar espaço aos conjuntos comerciais ou edifícios verticais - residenciais ou comerciais - é de $78,66 \%$ (59 unidades).

\section{Discussão e Considerações finais}

Em termos gerais, observa-se que alguns elementos arquitetônicos são mais vulneráveis frente à adaptação de residência em edificação comercial, como por exemplo os recuos e projeções, pois resultam no benefício do ganho de área para o estabelecimento ao subtrair "irregularidades" da volumetria e da fachada. Além desta, os jardins e telhados foram os elementos mais modificados; o primeiro, presente na maioria das residências no auge da avenida, agora estão cobertos por concreto e estacionamentos, e o segundo, considerados ultrapassados, escondem-se detrás de platibandas. A imagem da avenida residencial passa então a apresentar imagem inadequada na atualidade onde longas e desproporcionais vitrines sobrepõem as fachadas das antigas casas. Cores padronizadas, logomarcas e propagandas dominam as edificações reduzindo a qualidade arquitetônica ao mínimo grau.

A paisagem urbana histórica da Avenida Higienópolis torna-se vítima das exigências impostas pelo mercado varejista e pelo padrão de consumo contemporâneo, induzido pela marca. Percebe-se ainda que os setores da administração pública municipal não possuem organização política capaz de barrar a mutilações do Patrimônio Histórico, frente ao avanço do capital. Logo, os edifícios de caráter histórico são sujeitos às modificações impostas pelos comerciantes, proprietários e profissionais, os quais realizam adaptações de qualidade duvidosa, e são incapazes de conciliar a adequação do estabelecimento à preservação e valorização do patrimônio edificado.

As jovens cidades brasileiras, como Londrina, tendem a encontrar dificuldades para lidar com a voraz transformação imposta pelo mercado imobiliário e pelo capital varejista, comprometendo a integridade da paisagem urbana de seus centros históricos. Como consequência disso, uma área cultural sensível, passa a ser constituída de inúmeros tipos sincrônicos, com perda da historicidade. Para avaliar o grau das adaptações ocorridas, evocou-se os conceitos de Morfologia Urbana, testando os métodos de desenvolvimento do processo tipológico trabalhado por autores em contextos internacionais, avaliando sua aplicabilidade em uma cidade jovem como Londrina, em particular o caso da Avenida Higienópolis, obtendo-se resultados satisfatórios.

Alguma dificuldade pode ser relatada na etapa inicial de verificação do processo tipológico, relativa à definição dos períodos morfológicos, devido a juventude da cidade, e nível de acesso aos dados históricos. Acredita-se que em cidades mais velhas a percepção dos tipos formadores, e suas sobreposições ao longo do tempo, poderiam ser notados com mais clareza, possibilitando a delimitação de uma área cultural, e a definição de períodos morfológicos. 
A coleta das informações relativas às edificações pioneiras e à história de desenvolvimento da avenida também foi dificultada pela imprecisão de algumas importantes informações, e/ou pela precariedade do acesso das mesmas. O mesmo ocorre com a documentação e preservação dos dados cadastrais de edificações residências pioneiras, que, devido à manipulação inadequada e ao acesso público diário, se deterioram ou se perdem, colocando em risco a possibilidade de contato da cidade com seu passado.

Superadas as limitações do desenvolvimento deste trabalho, observa-se que o método de Gokce \& Chen (2018) necessitou de adaptações que tornassem a aplicação do processo tipológico realizável, sendo estas relativas ao método de análise do período morfológico, estipulação de fases, análise de continuidade ou mutação das permanências e terminologia utilizada para descrever e especificar a continuidade. Em contraponto, o método de análise do caráter da edificação histórica de Yamaki (2008), se mostrou mais aplicável e coerente ao objetivo deste trabalho. $O$ fato de ter sido elaborado para um contexto urbano e histórico semelhante ao estudo de caso aqui apresentado - cidades jovens do norte do Paraná - facilitou o entendimento e adequação. Logo, as adaptações necessárias para a aplicação do método na Avenida Higienópolis foram relativas aos elementos arquitetônicos considerados para a avaliação das permanências e à utilização de pontuação destes elementos. De modo geral, ambos os métodos foram adaptados, e se complementaram.

Em um cenário geral, ocorre no objeto de estudo utilizado por este trabalho um fenômeno semelhante ao apontado por Adams (2001), a destruição da identidade da cidade em prol do mercado, uniformizando as paisagens urbanas. Concordando com isto, Rodrigues et al (2019), descrevem que o processo de adaptações desenfreadas e massificadas unido à baixa qualidade arquitetônica promovem empobrecimento da paisagem urbana histórica e reduzem sua historicidade. Portanto, o avanço de métodos da Morfologia Urbana faz-se necessário para a propagação de uma cultura protecionista ao patrimônio arquitetônico, histórico e cultural de cidades brasileiras, independendo de seu tamanho ou idade, considerando que cada uma possui seu sentido cultural digno de ser preservado e valorizado.

\section{Agradecimentos}

Agradeço aos servidores do Museu Municipal Padre Carlos Weiss, da Biblioteca Municipal de Londrina e do Cadastro Imobiliário da Prefeitura de Londrina pela colaboração na obtenção de informações e documentos relacionados a esta pesquisa.

\section{Referências}

ADAMS, B. O patrimônio de Florianópolis: trajetória da gestão para uma preservação. Dissertação de Mestrado em Geografia. Florianópolis: UDESC, 2001. 
BATTY, M.; Longley, P. Fractual cities: a geometry of form and function. London: Academic Press, 1994.

BONI, P. C. Retratos da Cidade: $O$ uso de fotografia para recuperação de fragmentos históricos de Londrina. Londrina: Midiograf, 2014.

BURKAY, H. Ö. Social Policy of Urban Transformation: Social Housing Policies in Turkey from the 1980s to Present. Doctoral Thesis. Istanbul: Bosphorus University, 2006.

CANIGGIA, G.; Maffei, G. L. Architectural Composition and Building Typology. Firenze: Alinea Editrice, 2001.

CASTELNOU, A. M. Arquitetura londrinense: expressões de intenção pioneira. Londrina: Atrio Art Editorial, 2002.

CHEN, F., Thwaites. K. Chinese Urban Design: The Typomorphological Approach. Surrey: Ashgate, 2013.

COSTA, S. A.; Netto, M. M. Fundamentos de Morfologia Urbana. Belo Horizonte: Editora C/Arte, 2015.

COZEN, M. R. G. Alnwick, Northumberland: a study in town plan analysis. The Institute of British Geographers, nำ27, p. 859-864, 1960.

GOKCE, D.; Chen, F. A methodological framework for defining "tipological process": the transformation of the residential environment in Ankara, Turkey. Journal of Urban Design, p. 772-769, 2018.

LARKHAM, P; Jones, A. Research monograph. In: Historical Geography Research Group of the Institute of British Geographers, 1980. Disponível em: <http://www.urbanform.org/glossary.html>. Acesso em 22 jun. 2020.

MARSH, L.; Steadman, P. The geometry of environment. London: RIBA, 1971.

MURATORI, S. Studi Per Una Operanre Storia Urbana De Venezia. Roma: Istituto Poligraphico dello Stato, 1959.

RODRIGUES, E. R.; Rodrigues, B. M.; Cabrera, L. Da casa ao comércio: verificação dos graus de transformação de edificações residenciais no centro de Londrina (PR) por meio do processo tipológico. In: Conferência da rede lusófona de morfologia urbana, 8., Maringá, 21 a 23 ago. 2019. Anais da 8a Conferência da rede lusófona de morfologia urbana - PNUM 2019. Maringá, UEM, 2019. p. 619-635.

RODRIGUES, E. R. Shopping a céu aberto no Brasil: transformações, estratégias e perspectivas da rua comercial na sociedade de consumo contemporânea. Tese de Doutorado em Planejamento Urbano e Regional. São Carlos: FAUUSP, 2012. 
ROSSI, A. Consideraciones sobre la morfologia urbana y la tipologia contructiva. In: Aspetti e problemi dela tipologia edilizia. Venezia: Cluva, 1964.

TANGARI, V.; Amorim, F. P. Estudo Tipológico Sobre A Forma Urbana: Conceitos E Aplicações. Paisagens e Ambientes, № 22, p. 61-73, 2006.

YAMAKI, H. Caráter de edificações históricas. Londrina: Edições Humanidades, 2008.

YAMAKI, $\mathrm{H}$. Terras do norte: Paisagem e morfologia. Londrina: Editor Humberto Yamaki / UEL, 2017.

ZANGIROLANI, A. C. G. M. A Avenida Higienópolis de Londrina nos anos de 30 e 40. Dissertação de Mestrado em Arquitetura e Urbanismo. São Paulo: FAU, 2001. 